\title{
Efficacy of topical terbinafine and clotrimazole in the treatment of dermatophytoses: a Clinical and Microbiological Comparision.
}

\section{Nepal Anand ${ }^{1}$}

Senior Consultant Dermatologist, Department of Dermatology, Pokhara Academy of Health Sciences, Western Regional Hospital, Pokhara, Nepal

\section{Corresponding Author}

Dr. Anand Nepal,

Senior Consultant Dermatologist,

Department of Dermatology,

Pokhara Academy of Health Sciences,

Western Regional Hospital,

Pokhara, Nepal

E mail: anandnpl@gmail.com

Article received : February 6, 2018

Article accepted : March 13, 2018

\begin{abstract}
Background: Dermatophytoses have a high prevalence worldwide and also in Nepal. Large scale studies with different antifungal agents for long follow up periods to assess the long term outcome of treatments together with culture sensitivity testing are required to confirm the elimination of the fungi. Materials and Methods: Total of 97 patients were enrolled, 48 patients received treatment with terbinafine $1 \%$ cream for 2 weeks and 49 patients received clotrimazole $1 \%$ cream for 4 weeks. Clinical evaluation and microscopic examination of the potassium hydroxide $(\mathrm{KOH})$ mount were done at presentation, at week 2 and at week 4 . Clinical assessment scoring(CAS) and Mycological cure rate were compared between the study groups. Results : Terbinafine cured more cases of dermatophytoses compared to clotrimazole. The clinical cure rate was not statistically different among cases of tinea pedis. Terbinafine was better among cases of tinea cruris and tinea corporis only at the end of week 4 . Mycological cure rate was higher for terbinafine both at the end of week 2 and week 4 .
\end{abstract}

Keywords: Terbinafine, dermatophytosis, tinea, cruris, pedis, corporis.

\section{INTRODUCTION}

Dermatophytoses are group of disorders affecting skin, hair or nail involving the keratinized tissue. Clinical variants include Tinea capitis(T Capitis), Tinea cruris(T cruris), Tinea pedis(T pedis), Tinea corporis(T corporis), Tinea faciei, Tinea barbae, Tinea unguium and Tinea manum. ${ }^{1,2}$

Diagnosis of dermatophytosis is usually based on history and clinical appearance plus direct microscopy of a potassium hydroxide $(\mathrm{KOH})$ mounts of skin scrapings. Culture or histolopathological examinations are rarely required. Topical therapy is generally successful unless the infection covers an extensive area or is resistant to initial therapy. Tinea corporis and Tinea cruris infections are usually treated for two weeks. Tinea pedis is treated for four weeks with an azole or one to two weeks with an allylamine. Because topical antifungals do not penetrate hair or nails, Tinea capitis, Tinea barbae and Tinea unguium usually require systemic therapy. ${ }^{2}$
Terbinafine belongs to allylamine class of antifungal agent which inhibit the enzyme squalene epoxidase in the fungal cell membrane blocking the synthesis of ergosterol. They are considered fungicidal because the accumulation of intracellular squalene leads directly to cell death in a dose dependent manner. The cell death correlates closely with squalene accumulation. ${ }^{3}$ Clotrimazole belongs to imidazole class of antifungal drugs. Imidazoles inhibit lanosterol 14- $\alpha$ demethylase, a cytochrome P-450 dependent enzyme which is required for conversion of lanosterol to ergosterol. Imidazoles are fungistatic drugs. ${ }^{4}$

This study was undertaken with the objective to determine the effectiveness of terbinafine $1 \%$ cream compared to clotrimazole $1 \%$ cream in Tinea pedis/cruris/corporis/ manum/faciei.

\section{MATERIALS AND METHODS}

Observational clinical study was done at Shree Birendra Hospital, Chauni, Kathmandu between July $1^{\text {st }} 2011$ to 
June $3^{\text {rd }} 2012$ A.D. Any patient above the age of 12 years presenting to the dermatology outpatient department and diagnosed as Tinea pedis, Tinea cruris, Tinea corporis were included. Consent was obtained from all patients and ethical clearance was taken.

Patients with more than $10 \%$ skin surface involvement, concurrent skin conditions which can interfere with the clinical evaluation on subsequent visits, severe systemic diseases, history of treatment with oral or topical antifungal drugs in the previous 4 weeks, known hypersensitivity to allylamines/azoles, Tinea capitis, Tinea unguium, Tinea barbae and patient who refuse to participate in the study were excluded.

Each patient was allocated to either terbinafine or clotrimazole group. The terbinafine group were prescribed terbinafine $1 \%$ cream to be applied twice daily to cover the affected area upto $2 \mathrm{~cm}$ beyond the lesion for 2 weeks. The clotrimazole group were prescribed clotrimazole $1 \%$ cream to be applied twice daily for 4 weeks with similar coverage. All the patients were re-evaluated at the end of week 2 and week 4. In each visit, Clinical Assessment Scoring (CAS) was done, any adverse events noted and $\mathrm{KOH}$ mounts of skin scrapings were evaluated by microscopy.

$P$ value was calculated under the predetermined level of significance (0.05) and confidence interval of $95 \%$ was constructed. SPSS 17 was used to generate all desired values. Chi-square test and descriptive test were used for the comparative study.

This study can contribute to increased compliance of topical antifungals, primarily owing to the shorter course of allylamines compared to imidazoles.

\section{RESULTS}

Total of ninety seven cases, Tinea cruris $(n=29)$, Tinea corporis $(n=30)$, and Tinea pedis $(n=38)$ were enrolled for the study. Sixty five patients were available for assessment at the end of week 2 and sixty four at the end of week 4 .

In this study, terbinafine $1 \%$ cream applied twice daily for 2 weeks was better in dermatophytoses compared to clotrimazole $1 \%$ cream applied twice daily for 4 weeks. No any adverse events were noted for either of the drugs.

Reduction in Clinical Assessment Scoring (CAS) was significantly better in favor of terbinafine both at the end of week 2 as well as week 4 .

Among the patients enrolled and who maintained follow up, $40 \%$ of terbinafine group and $11.6 \%$ of clotrimazole group acheived clinical cure at the end of week 2, whereas $75.2 \%$ of terbinafine group and $31.4 \%$ of clotrimazole group achieved clinical cure at the end of week 4.

Among the patients of Tinea pedis treated with terbinafine , 50\% achieved clinical cure at the end of week 2 and $62.5 \%$ at the end of week 4 and among those treated with clotrimazole, $16 \%$ achieved clinical cure at the end of week 2 and $46.2 \%$ achieved it at week 4. Terbinafine cured more cases of $\mathrm{T}$. pedis compared to clotrimazole. The difference was not statistically significant $(\mathrm{p}=0.27$ week 2 and $\mathrm{p}=0.78$ week 4 ).

In our study among the patients treated for $\mathrm{T}$ cruris and $\mathrm{T}$ corporis the cure rate of terbinafine was significantly better than clotrimazole.

Table 1. Group wise differential of Clinical Area Severity CAS at different visits among all the cases.

\begin{tabular}{|c|c|c|c|c|c|}
\hline \multicolumn{6}{|c|}{ Group Statistics } \\
\hline & Treatment & $\mathrm{N}$ & Mean & Std. Deviation & $\mathrm{P}$ \\
\hline \multirow{2}{*}{ CASO } & Terbinafine & 48 & 6.23 & 3.302 & .520 \\
\hline & Clotrimazole & 49 & 6.63 & 2.977 & \\
\hline \multirow{2}{*}{ CAS2 } & Terbinafine & 36 & 2.64 & 2.800 & .005 \\
\hline & Clotrimazole & 39 & 4.41 & 2.531 & \\
\hline
\end{tabular}

\begin{tabular}{|c|c|c|c|c|c|c|c|}
\hline & \multicolumn{3}{|c|}{ Terbinafine } & \multicolumn{4}{|c|}{ Clotrimazole } \\
\hline & Q1 & Md & Q3 & Q1 & $\mathrm{Md}$ & Q3 & $\mathrm{P}$ \\
\hline CAS4 & .00 & 1.00 & 1.75 & 1.75 & 2.00 & 4.00 & .01 \\
\hline
\end{tabular}

The mycological cure rate in our study was $76.9 \%$ at week 2 and $91.7 \%$ at week 4 for terbinafine and $75 \%$ at week 2 and $84.6 \%$ at week 4 for clotrimazole as seen in table 2 and 3 respectively. 
Table 2. Mycological cure rate at week 2

\begin{tabular}{|c|c|c|c|c|c|c|c|}
\hline \multirow{2}{*}{\multicolumn{4}{|c|}{ Treatment }} & \multicolumn{2}{|l|}{$\mathrm{KOH} 2$} & \multirow{2}{*}{ Total } & \multirow{3}{*}{$\begin{array}{l}\mathrm{P} \text { value } \\
0.002\end{array}$} \\
\hline & & & & +ve & -ve & & \\
\hline \multirow{6}{*}{ Terbinafine } & \multirow{4}{*}{$\mathrm{KOHO}$} & \multirow{2}{*}{$+\mathrm{ve}$} & Count & 3 & 10 & 13 & \\
\hline & & & $\%$ within $\mathrm{KOH} 0$ & $23.1 \%$ & $76.9 \%$ & $100.0 \%$ & \\
\hline & & \multirow{2}{*}{-ve } & Count & 0 & 17 & 17 & \\
\hline & & & $\%$ within $\mathrm{KOH} 0$ & $.0 \%$ & $100.0 \%$ & $100.0 \%$ & \\
\hline & \multirow{2}{*}{\multicolumn{2}{|c|}{ Total }} & Count & 3 & 27 & 30 & \\
\hline & & & $\%$ within $\mathrm{KOH} 0$ & $10.0 \%$ & $90.0 \%$ & $100.0 \%$ & \\
\hline \multirow{6}{*}{ Clotrimazole } & \multirow{4}{*}{$\mathrm{KOHO}$} & \multirow{2}{*}{$+\mathrm{ve}$} & Count & 4 & 12 & 16 & 0.003 \\
\hline & & & $\%$ within $\mathrm{KOH} 0$ & $25.0 \%$ & $75.0 \%$ & $100.0 \%$ & \\
\hline & & \multirow{2}{*}{-ve } & Count & 1 & 16 & 17 & \\
\hline & & & $\%$ within $\mathrm{KOH} 0$ & $5.9 \%$ & $94.1 \%$ & $100.0 \%$ & \\
\hline & \multirow{2}{*}{\multicolumn{2}{|c|}{ Total }} & Count & 5 & 28 & 33 & \\
\hline & & & $\%$ within $\mathrm{KOH} 0$ & $15.2 \%$ & $84.8 \%$ & $100.0 \%$ & \\
\hline
\end{tabular}

Table 3. Mycological Cure rate at the end of week 4

\begin{tabular}{|c|c|c|c|c|c|c|c|}
\hline & & Treat & & $\mathrm{KOH}$ & & Total & \\
\hline & & real & & +ve & -ve & & $P$ value \\
\hline & & & Count & 1 & 11 & 12 & 0.001 \\
\hline & КОНО & +ve & $\%$ within $\mathrm{KOH} 0$ & $8.3 \%$ & $91.7 \%$ & $100.0 \%$ & \\
\hline & NUחU & & Count & 0 & 11 & 11 & \\
\hline Terbinafine & & $-v e$ & $\%$ within $\mathrm{KOHO}$ & $.0 \%$ & $100.0 \%$ & $100.0 \%$ & \\
\hline & Total & & Count & 1 & 22 & 23 & \\
\hline & & & $\%$ within $\mathrm{KOH} 0$ & $4.3 \%$ & $95.7 \%$ & $100.0 \%$ & \\
\hline & & & Count & 2 & 11 & 13 & 0.006 \\
\hline & КОНО & + ve & $\%$ within $\mathrm{KOH} 0$ & $15.4 \%$ & $84.6 \%$ & $100.0 \%$ & \\
\hline Clotrimazole & NUחU & & Count & 1 & 13 & 14 & \\
\hline & & - ve & $\%$ within $\mathrm{KOH} 0$ & $7.1 \%$ & $92.9 \%$ & $100.0 \%$ & \\
\hline & Total & & Count & 3 & 24 & 27 & \\
\hline & & & $\%$ within $\mathrm{KOH} 0$ & $11.1 \%$ & $88.9 \%$ & $100.0 \%$ & \\
\hline
\end{tabular}

\section{DISCUSSION}

This result is similar to studies by Schopfman $\mathrm{R}$ et al, Evans EG et al and Evans EG, Dodman B et al. ${ }^{5-7}$ In all these studies terbinafine cream applied for 2 weeks followed by placebo was compared with 4 weeks of clotrimazole cream and all the studies done were in cases of Tinea pedis. In most of these studies the assessment had only been done at the end of week 4 and no data exists regarding the assessment at the end of week 2 .

In our study clinical cure was defined as score of 1 or less for Tinea cruris and Tinea corporis as defined by Singal A et al and 2 or less in Tinea pedis as defined by Schopf R et al. ${ }^{5,8}$

Among the patients enrolled and who maintained follow up, $40 \%$ of terbinafine group and $11.6 \%$ of clotrimazole group achieved clinical cure at week 2, whereas $75.2 \%$ of terbinafine group and $31.4 \%$ of clotrimazole group achieved clinical cure at week 4 .

Terbinafine cured more cases of $\mathrm{T}$. pedis compared to clotrimazole. The difference was not statistically significant. In our study all the clinically diagnosed cases of $\mathrm{T}$ pedis were included which increased the chance of non-dermatophyte moulds and candidal intertrigo being included. These conditions are less responsive to terbinafine, particularly candidiasis (only fungistatic affect), compared to dermatophytes against which terbinafine has fungicidal affect. The azole group of drugs are the topical treatment of choice in cases of candidiasis. $^{2,9-10}$

In our study among the patients treated for $\mathrm{T}$ cruris and $\mathrm{T}$ corporis the cure rate to terbinafine was significantly 
better than clotrimazole and the result is similar to many studies comparing the two drugs. These clinical cure rates are lower than seen in many other studies, which have been done comparing terbinafine cream with placebo by Greer DL et al (1992), Budimulja U et al (2002), Evans E et al (1992), Villars V et al (1989) and clotrimazole cream with placebo by Spiekermann PH (1978) $)^{11-15}$

In these studies, all the cases were culture proven dermatophytoses and non-dermatophyte infections had been excluded but all the clinically diagnosed cases were included in our study.

\section{REFERENCES}

1. Yehia MA, El-Ammawi TS, Al-Mazidi KM, El-Ela MAA, AlAjmi HS. The spectrum of fungal infections with a special reference to dermatophytoses in the Capital area of Kuwait during 2000-2005: A retrospective analysis. Mycopathologia. 2010;169(4):241-6.

2. Brennan B, Leyden JJ. Overview of topical therapy for common superficial fungal infections and the role of new topical agents. Vol. 36, Journal of the American Academy of Dermatology. 1997.

3. Ryder NS. Terbinafine: Mode of action and properties of the squalene epoxidase inhibition. Br J Dermatol. 1992;126:2-7.

4. Gupta AK, Einarson TR, Summerbell RC, Shear NH. An overview of topical antifungal therapy in dermatomycoses. A North American perspective. Vol. 55, Drugs. 1998. p. 645-74.

5. Schopf R, Hettler O, Br??utigam M, Weidinger G, Kaben U, Mayser P, et al. Efficacy and tolerability of terbinafine $1 \%$ topical solution used for 1 week compared with 4 weeks clotrimazole $1 \%$ topical solution in the treatment of interdigital tinea pedis: A randomized, double-blind, multi-centre, 8-week clinical trial. Mycoses. 1999;42(5-6):415-20.

6. Evans EGV. A comparison of terbinafine (Lamisil®) $1 \%$ cream given for one week with clotrimazole (Canesten $\left.{ }^{\circledR}\right)$ 1\% cream given for four weeks, in the treatment of tinea pedis. Br J Dermatol. 1994;130:12-4.

7. Evans EGV, Bodman B, Williamson DM, Brown GJ, Bowen RG. Comparison of terbinafine and clotrimazole in treating tinea pedis. Br Med J [Internet]. 1993;307(6905):645-7. Available from: http:// www.scopus.com/inward/record.url?eid=2-s2.0-0027283821\&partne

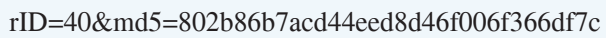

8. Singal A, Pandhi D, Agrawal S, Das S. Comparative efficacy of topical $1 \%$ butenafine and $1 \%$ clotrimazole in tinea cruris and tinea corporis: A randomized, double-blind trial. J Dermatolog Treat. 2005;16(5-6):331-5.

9. Huang DB, Ostrosky-Zeichner L, Wu JJ, Pang KR, Tyring SK. Therapy of common superficial fungal infections. Vol. 17, Dermatologic Therapy. 2004. p. 517-22.
The mycological cure rate in our study is similar with many other studies. Terbinafine cured more cases mycologically. ${ }^{5-6,16-20}$

\section{CONCLUSION}

Terbinafine was better compared to clotrimazole in the treatment of dermatophytoses. Larger studies with longer follow up periods and culture testing to exclude non dermatophyte infections are needed.

10. Singal A, Khanna D. Onychomycosis: Diagnosis and management. Indian J Dermatology, Venereol Leprol [Internet]. 2011;77(6):659. Available from: http://www.ijdvl.com/text.asp?2011/77/6/659/86475

11. Greer DL, Jolly HW. Treatment of tinea cruris with topical terbinafine. J Am Acad Dermatol. 1990;23(4):800-4.

12. Budimulja U, Bramono K, Urip KS, Basuki S, Widodo G, Rapatz $\mathrm{G}$, et al. Once daily treatment with terbinafine $1 \%$ cream (Lamisil@) for one week is effective in the treatment of tinea corporis and cruris. A placebo-controlled study. Mycoses. 2001;44(7-8):300-6.

13. Evans E, Shah J, Joshipura R. One-week treatment of tinea corporis and tinea cruris with terbinafine (lamisil) 1\% cream: A placebo-controlled study. J Dermatolog Treat. 1992;3(4):181-4.

14. Villars V, Jones TC. Clinical efficacy and tolerability of terbinafine (Lamisil) a new topical and systemic fungicidal drug for treatment of dermatomycoses. Clin Exp Dermatol. 1989;14(2):124-7.

15. Spiekermann PH, Young MD. Clinical Evaluation of Clotrimazole: A Broad-Spectrum Antifungal Agent. Arch Dermatol. 1976;112(3):350-2.

16. Ryder NS. The mechanism of action of terbinafine. Clin Exp Dermatol. 1989;14(2):98-100.

17. Clayton YM. Relevance of broadnspectrum and fungicidal activity of antifungals in the treatment of dermatomycoses. Br J Dermatol. 1994;130:7-8.

18. Sugiura M, Hata Y, Fukuda T, Ishizaki S, Hanyaku H, Naka W, et al. One-week application of terbinafine cream compared with fourweek application in treatment of tinea pedis. Japanese J Med Mycol. 2001;42(4):223-8

19. Sahoo AK, Mahajan R. Management of tinea corporis, tinea cruris and tinea pedis: A comprehensive review. Indian Dermatol Online J. 2016 Mar-Apr; 7(2):77-86

20. Sumyuktha J, Narashimhan M, Ahamed PV. A comparative trial between the therapeutic efficacy of topical $2 \%$ sertaconazole cream and $1 \%$ terbinafine cream in the treatment of tinea cruris/tinea corporis. Int J Res Dermatol. 2017 Mar; 3(1): 59-63. 